\title{
O Princípio da Dignidade da Pessoa Humana como Fundamento da Justiça Restaurativa a Partir do Pensamento de Immanuel Kant
}

\section{Eluane de Lima Corrales}

Advogada. Mestre do Programa de Pós-Graduação em Ciência Jurídica da Universidade Estadual do Norte do Paraná. Pós-graduanda em Direito Público pela Universidade Estácio de Sá. Bacharela em Direito pela Universidade Estadual do Norte do Paraná (Uenp). Realiza pesquisas sobre Justiça Restaurativa Juvenil e áreas afins à criminalidade infanto-juvenil, com destaque no estudo de medidas preventivas e ressocializadoras. Possui interesse em Direitos Humanos, Direito Penal e Direito Constitucional. Experiência na área de Direito, com ênfase em Direito Constitucional. http://lattes.cnpq.br/4203484134330173. eluanecorrales@hotmail.com

\section{Carla Bertoncini}

Doutora em Direito pela Pontifícia Universidade Católica de São Paulo (PUC, 2011). Mestre em Direito (2001) e Bacharela em Direito (1992) pela Instituição Toledo de Ensino (ITE). Professora-adjunta do curso de Pós-Graduação Stricto Sensu (Mestrado) e do curso de Graduação da Faculdade de Direito do Centro de Ciências Sociais Aplicadas da Universidade Estadual do Norte do Paraná (Uenp, Campus de Jacarezinho) e professora de Direito Civil (Direito de Família) das Faculdades Integradas de Ourinhos (FIO). Advogada. http://lattes.cnpq.br/8287398590266450. bertoncinicarla@uol.com.br

$\mathrm{Na}$ atual sistemática apresentada pela justiça comum brasileira, observa-se que vítima e ofensor recebem um tratamento meramente formal por parte do Estado, não tendo suas necessidades psicológicas e emocionais atendidas, sendo tratadas apenas como objetos do sistema jurídico e não como pessoas que possuem razão e sentimentos. Nesse sentido, o presente artigo busca a resposta do seguinte questionamento: O que pode ser feito para que vítimas e ofensores possuam suas dignidades respeitadas no atual processo penal? A principal hipótese para a resolução de tal questionamento afirma que, conforme a concepção kantiana de Dignidade da Pessoa Humana, a Justiça Restaurativa poderia ser utilizada como um método alternativo ou complementar de resoluções de conflitos para que tal dignidade possa ser alcançada. Mediante os métodos de pesquisa indutivo e qualitativo, com técnica de procedimento bibliográfico, conclui-se que as práticas restaurativas são essenciais para que a dignidade da pessoa humana seja realmente alcançada em resoluções de conflitos.

Palavras-chave: Justiça restaurativa. Princípio. Dignidade da pessoa humana. Immanuel Kant. Punição.

\section{THE PRINCIPLE OF THE DIGNITY OF THE HUMAN PERSON AS A FOUNDATION} OF RESTORATIVE JUSTICE WITHIN IMMANUEL KANT'S THOUGHT

\section{ABSTRACT}

In the current systematics presented by the Brazilian common justice, it is observed that the victim and offender receive a purely formal treatment by the State, not having their psychological and emotional needs met, being treated only as objects of the legal system and not as persons who are right and feelings. In this sense, the present article seeks to answer the following question: what can be done so that victims and offenders have their dignities respected in the current criminal process? The main hypothesis for solving this questioning is that according to the Kantian conception of Human Dignity, Restorative Justice could be used as an alternative or complementary method of conflict resolution so that such dignity can be achieved. Through the methods of inductive and qualitative research, with method of bibliographical procedure, it is concluded that restorative practices are essential so that the dignity of the human person is actually reached in resolutions of conflicts.

Keywords: Restorative justice. Principle. Dignity of human person. Immanuel Kant. Punishment.

SUMÁRIO

1 Introdução. 2 A Dignidade da Pessoa Humana: Histórico e Conceitos. 3 Justiça Restaurativa: Um Novo Olhar sobre a Pessoa Humana. 4 A Dignidade da Pessoa Humana Como Princípio da Justiça Restaurativa a Partir da Visão Kantiana. 5 Conclusão. 6 Referências. 


\section{INTRODUÇÃO}

Durante toda a história da humanidade buscam-se mecanismos para que práticas de violências e crimes sejam coibidas, bem como há a incansável procura por meios eficazes para a aplicação de punição a todos aqueles que transgridam às regras existentes no ordenamento jurídico. Ocorre que os atuais meios de punição não estão atingindo tais finalidades, não possuindo nenhum caráter ressocializador ou preventivo.

Ademais, tais punições são verdadeiras evoluções dos antigos castigos, em que o caráter vingativo da pena fica apenas mascarado pela legalidade que envolve todo o sistema penal. A vítima é vista somente como mero objeto do processo, não possuindo nenhuma prerrogativa acerca de seus sentimentos e necessidades psicológicas. Já o ofensor é visto como um indivíduo que pode aguentar todos os males ocasionados pela pena que lhe é imposta, não recebendo nenhum atendimento diferenciado e humanitário que tenha como objetivo a sua ressocialização.

A partir de tais premissas, faz-se o seguinte questionamento: $O$ que pode ser feito para que vítimas e ofensores possuam suas dignidades respeitadas no atual processo penal? A principal hipótese para a resolução de tal questionamento afirma que, conforme a concepção kantiana de Dignidade da Pessoa Humana, a Justiça Restaurativa poderia ser utilizada como um método alternativo ou complementar de resoluções de conflitos para que tal dignidade possa ser alcançada. O objetivo geral da presente pesquisa é a análise da Dignidade da Pessoa Humana como princípio da Justiça Restaurativa, por meio da apresentação da construção histórica de seus variados sentidos, com enfoque na concepção do Filósofo Immanuel Kant.

$\mathrm{O}$ artigo apresenta-se sob os métodos de abordagem indutivo e qualitativo, com técnica de procedimento bibliográfico, na qual foi analisada a evolução histórica dos conceitos de dignidade humana mediante a apresentação da construção histórica de seus variados sentidos, com enfoque na concepção do filósofo Immanuel Kant. A partir de tal concepção, foi realizado um paralelo entre suas principais características e os fundamentos da Justiça Restaurativa, bem como a análise se tal modelo de resolução de conflitos oferece dignidade à vítima e ao ofensor.

\section{A DIGNIDADE DA PESSOA HUMANA: HISTÓRICO E CONCEITOS}

A dignidade da pessoa humana possui extrema importância na seara constitucional, além de ser alicerce e base fundante dos direitos fundamentais. É elencada no Título I, artigo 1ำ, da Constituição da República Federativa do Brasil, no qual integra os fundamentos da República e do Estado Democrático de Direito, sendo um de seus princípios fundamentais, conforme observado, in verbis:

A República Federativa do Brasil, formada pela união indissolúvel dos Estados e Municípios e do Distrito Federal, constitui-se em Estado Democrático de Direito e tem como fundamentos:

I- a soberania;

II - a cidadania;

III - a dignidade da pessoa humana;

IV - os valores sociais do trabalho e da livre iniciativa;

V - o pluralismo político; (BRASIL, 1988). 


\section{Humanos e \\ Democracia}

Nesse contexto, Vanessa De Biassio Mazzutti (2012, p. 38) ressalta que "a partir dessas premissas, vislumbra-se que a dignidade resta concebida como atributo intrínseco a qualquer pessoa humana, motivo pelo qual foi enquadrada como princípio constitucional absoluto na maioria das Constituições modernas [...]". Na mesma linha, Edgar Hrycylo Bianchini (2012, p. 71) aduz que "tal elemento é um dos princípios mais importantes de Direito e funciona como viga mestra ao ordenamento jurídico contemporâneo", posto que todos os outros princípios, direitos e garantias fundamentais existentes são nele pautados.

Ademais, a dignidade também é expressa em diversos documentos internacionais. Como exemplo pode-se citar a Declaração Universal de Direitos Humanos, de 1948, a qual já fazia menção à dignidade, em seu artigo 1ㅇ, ao declarar que todas as pessoas nascem livres e iguais em dignidade e direitos. Acerca do assunto, Luís Roberto Barroso (2014, p. 29-30) elenca os diversos tratados e declarações existentes no Direito Internacional que fazem menção a este importante princípio:

Carta da ONU (1945), a Declaração Universal dos Direitos do Homem (1948), a Convenção Internacional para a Eliminação de Todas as Formas de Discriminação Racial (1965), o Pacto Internacional de Direitos Civis e Políticos (1966), o Pacto Internacional de Direitos Econômicos, Sociais e Culturais (1966), a Convenção Americana de Direitos Humanos (1978), a Convenção sobre a Eliminação de Todas as Formas de Discriminação contra as Mulheres (1979), a Carta Africana de Direitos Humanos e dos Povos (1981), a Convenção contra a Tortura e Outros Tratamentos Cruéis, Desumanos ou Degradantes (1984), a Convenção de Direitos da Criança (1989), a Carta dos Direitos Fundamentais da União Europeia (2000), e a Carta Árabe de Direitos Humanos (2004), entre outros.

Conforme os ensinamentos de Oscar Vilhena Vieira (2006, p. 63), o constituinte, ao elencar a dignidade da pessoa humana como um dos fundamentos da República Federativa do Brasil, proporcionou a este princípio um caráter multidimensional, não apresentando a forma de mero direito subjetivo, mas, sim, condição de existência para todos os direitos fundamentais, os quais guardam íntima relação com a vida humana.

Ademais, partindo das premissas analisadas a posteriori, pode-se concluir que "a dignidade da pessoa humana consolida-se como um dos fundamentos do Estado Democrático de Direito" (GARCIA JÚNIOR, 2017, p. 142). Nesse sentido, cabe ao Estado a oferta de condições mínimas para a existência humana, proporcionando a todos a garantia dos direitos fundamentais previstos na Constituição da República Federativa do Brasil (MAZZUTTI, 2012, p. 38). Ressalta-se, ainda, que em um Estado Democrático de Direito a dignidade humana deve ser vista como um direito inerente à humanidade, devendo sempre ser um objetivo a ser alcançado.

Desta forma, para que o amplo sentido de dignidade da pessoa humana seja atingido, faz-se necessário resgatar o contexto histórico em que tal princípio passou a existir, tornando-se integrante do âmbito jurídico. Conforme Ingo Wolfgang Sarlet, pode-se afirmar que a Dignidade da Pessoa Humana possui raízes ainda no pensamento clássico e nos ideais pautados no Cristianismo. Tal premissa não pode ser comprovada, porém possui fundamento no fato de existirem trechos bíblicos no Novo e no Antigo Testamentos, nos quais o ser humano é descrito como sendo a imagem e a semelhança de Deus e, por este fato, não pode ser visto ou transformado em objeto ou em um simples instrumento (SARLET, 2006, p. 29). 
No que se refere ao pensamento desenvolvido na Antiguidade Clássica, não eram todos os homens que possuíam dignidade. Segundo o pensamento filosófico e político da época, a dignidade era medida conforme a classe social de cada indivíduo, posicionamento que muda com o advento do estoicismo. Nesse sentido, pontua Ingo Wolfgang Sarlet (2006, p. 30):

No pensamento filosófico e político da antiguidade clássica, verifica-se que a dignidade (dignitas) da pessoa humana dizia, em regra, com a posição social ocupada pelo indivíduo e o seu grau de reconhecimento pelos demais membros da comunidade, daí poder falar-se em uma quantificação e modulação da dignidade, no sentido de se admitir a existência de pessoas mais dignas ou menos dignas. Por outro lado, já no pensamento estóico, a dignidade era tida como a qualidade que, por ser inerente ao ser humano, o distinguia das demais criaturas, no sentido de que todos os seres humanos são dotados da mesma dignidade, noção esta que se encontra, por sua vez, intimamente ligada à noção da liberdade pessoal de cada indivíduo (o Homem como ser livre e responsável por seus atos e seu destino), bem como à idéia de que todos os seres humanos, no que diz com a sua natureza, são iguais em dignidade.

Durante a Idade Média, essas concepções de dignidade da pessoa humana continuaram sendo sustentadas. Luís Roberto Barroso (2014, p.13) explica que desde a Roma antiga até o Estado Liberal o conceito de dignidade era associado ao status pessoal de indivíduos ou à proeminência de instituições.

O citado autor, todavia, faz uma ressalva quanto à evolução histórica de tal princípio ao observar que o atual significado dado à dignidade da pessoa humana não poderia ser originário de um pensamento romano pautado na hierarquização e segregação de indivíduos. Ressalta, ainda, que os atuais conceitos empregados a tal princípio são provenientes de influências religiosas e filosóficas que ocorreram simultaneamente ao contexto histórico romano.

Tais influências religiosas e filosóficas levaram à construção de uma concepção que fundamentava a dignidade da pessoa humana no fato de o homem ser feito à imagem e semelhança de Deus, bem como em possuir a capacidade de tomar suas próprias decisões. $A$ respeito do aspecto religioso, tem-se por ponto de partida o monoteísmo hebraico, no qual os pensamentos mais relevantes a respeito da dignidade humana eram encontrados na Bíblia Judaica. Tais pensamentos seriam, posteriormente, repetidos no Novo Testamento Cristão (BARROSO, 2014, p. 15).

Há, porém, que se ressaltar que muitos ideais defendidos pelo Cristianismo, como premissas de amor ao próximo, igualdade e solidariedade, nem sempre foram respeitados por esse segmento religioso, conforme lembrado pelos registros históricos, como nos casos das perseguições e dos cruéis castigos proporcionados aos hereges.

Como observado, durante toda a Idade Média a concepção de dignidade humana esteve pautada nos ideários religiosos. Já no período renascentista, Giovanni Picco dela Mirandola destacou-se por afirmar que "sendo criatura de Deus, ao Homem [...] foi outorgada uma natureza indefinida, para que fosse seu próprio árbitro, soberano e artífice, dotado da capacidade de ser e obter aquilo que ele próprio quer e deseja" (SARLET, 2006, p. 32). 


\section{Humanos e \\ Democracia}

Conforme assevera Luís Roberto Barroso, em 1486 Giovanni Picco afasta a ratio philosophica da subordinação até então existente à ratio theologica. Tais pensamentos do "Conde de Mirandola" foram responsáveis pela proibição da circulação de suas teses, uma vez que a Inquisição as considerou heréticas (BARROSO, 2014, p. 17).

Fica claro, portanto, o caráter racional que o princípio da dignidade da pessoa humana começa a obter com o alvorecer do Renascentismo. É com o jusnaturalismo, porém, que tal concepção fica totalmente desvinculada dos ideários cristãos. Nesse período, destacam-se os pensamentos de Samuel Pufendorf e Immanuel Kant.

Conforme descrito por Luís Roberto Barroso (2014, p. 17), o filósofo alemão Samuel Pufendorf foi "um precursor do lluminismo e um pioneiro na concepção secular de dignidade humana, a qual ele fundou sobre a liberdade moral". Com o alvorecer do lluminismo, o nome que ganhou destaque em relação às análises realizadas acerca da dignidade humana foi o de Immanuel Kant.

Para Kant, no reino dos fins tudo possui um preço ou uma dignidade. O filósofo afirmava que quando uma coisa está acima de todo o preço, sendo insubstituível, possuiria, então, dignidade. Dessa forma, coisas possuem preço, já pessoas possuem um valor absoluto, chamado dignidade. Destarte, cada pessoa deve ser vista como sendo um fim em si mesma, detentora de dignidade, e não como coisas, as quais são utilizadas discricionariamente (BARROSO, 2014, p. 17).

Com seu Imperativo Categórico, o qual consiste em "uma ação que é boa em si mesma, independentemente do fato de servir a determinado fim" (BARROSO, 2014, p. 71), Kant tratou o princípio da dignidade tendo em vista duas perspectivas: a substantiva e a formal. Oscar Vilhena Vieira (2006) explica esses posicionamentos através do olhar kantiano. Sob o aspecto substantivo, a dignidade é pautada no fato de que o homem deve ser visto enquanto fim em si mesmo. Dessa forma, sob essa ótica, o homem nunca pode ser tratado como um meio, sendo visto, apenas, como um objeto ou servindo para a simples concretização de outros objetivos.

Já pela visão formal, Kant remete a dignidade da pessoa humana ao fato de as pessoas terem como dever se tratarem com imparcialidade e respeito. Tal fato dá-se pela estreita relação com o aspecto substantivo, uma vez que, sendo um fim em si, todos os indivíduos devem ser mutuamente respeitados (VIEIRA, 2006, p. 67).

Neste sentido, pontua Oscar Vilhena Vieira (2006, p. 65-66):

A ideia de dignidade humana, está, portanto, vinculada à nossa capacidade de nos conduzirmos pela nossa razão e não nos deixarmos arrastar apenas pelas nossas paixões. Consultada nossa razão, como diria Rousseau, o ser humano pode conceber o que é certo e o que é errado, o que é moral do que é imoral, e seu livre arbítrio o habilitará a seguir um ou outro caminho. A autonomia é, assim, um pressuposto da moralidade.

Igualmente, Ingo Wolfgang Sarlet (2006, p. 33) salienta o pensamento racional kantiano ao afirmar que, para Kant, a dignidade da pessoa humana é encontrada apenas nos seres racionais, ou seja, somente naqueles que possuem capacidade de autodeterminação. 
Sobre tal vertente, o citado autor faz uma crítica ao pensamento de Kant no sentido de que tal ideário racional, acerca da abrangência da dignidade, é muito antropocentrista, sendo o homem o único indivíduo a retê-la, ficando, assim, em uma posição de superioridade sobre os demais seres vivos que habitam nosso planeta.

$\mathrm{Na}$ atualidade, porém, tal pensamento é alvo de inúmeras teses e constitui um desafio a todos que defendem que a dignidade não é um atributo apenas dos seres dotados de racionalidade, mas, sim, de todos aqueles seres que possuem vida. Fato é que, nas palavras de Ingo Wolfgang Sarlet (2006, p. 35), "de qualquer modo, incensurável, isto sim [...] é a permanência da concepção kantiana no sentido de que a dignidade da pessoa humana, esta (pessoa) considerada como fim e não como meio, repudia toda e qualquer espécie de coisificação e instrumentalização do ser humano".

No atual cenário brasileiro, no entanto, vem ocorrendo a constante banalização dos diversos sentidos que podem ser atribuídos à dignidade humana, os quais estão sendo utilizados indiscriminadamente como justificativa para diversos questionamentos. Neste sentido, Dimitri Dimoulis e Leonardo Martins (2014, p. 77) ressaltam que, em decorrência do constante uso do argumento da dignidade da pessoa humana de forma metodologicamente indisciplinada e jurídico-dogmaticamente incorreta, o maior problema e risco é que um dos valores mais importantes e positivados pelo constituinte brasileiro seja grandemente desvalorizado quando bagatelizado.

Além disso, muitos autores fazem a distinção entre a dignidade humana e o princípio da dignidade da pessoa humana, conforme apresentado por Ingo Wolfgang Sarlet (2007, p. 374):

É também nesta perspectiva que há, de fato, como traçar uma distinção entre dignidade humana (aqui no sentido da dignidade reconhecida a todos os seres humanos, independentemente de sua condição pessoal, concreta) e dignidade da pessoa humana, concretamente considerada, no contexto de seu desenvolvimento social e moral.

Cumpre aqui ressaltar que os princípios jurídicos possuem significado diverso das regras, as quais podem ser subsumidas a situações fáticas predeterminadas. Os princípios dependem, acima de tudo, de serem concretizados. Consoante assevera Karl Larenz (1997, p. 599), é necessário realizar uma diferenciação dos graus de concretização dos princípios, posto que, "no grau mais elevado, o princípio não contém ainda nenhuma especificação de previsão e consequência jurídica, mas só uma ideia jurídica geral, pela qual se orienta a concretização ulterior como por um fio condutor". O autor ressalta, ainda, que é nessa espécie que se encontra o Princípio da Dignidade da Pessoa Humana.

Faz-se necessária, portanto, a observação do contexto de cada caso concreto no qual esse princípio será interpretado, para que possa ser aplicado em sua melhor acepção, de acordo com as peculiaridades de cada situação específica.

\section{JUSTIÇA RESTAURATIVA: UM NOVO OLHAR SOBRE A PESSOA HUMANA}

O histórico das sanções penais, ao longo dos séculos, é diverso e regado com muita violência e dor. Nos primórdios das civilizações, as penas aplicadas eram extremamente cruéis e configuravam-se em vinganças privadas (BIANCHINI, 2012, p. 20). 


\section{Humanos e \\ Democracia}

Com a transição da vingança aplicada pelo particular para a vingança aplicada por um poder central, no entanto, a pena passou, apenas, a ser parte de um sistema punitivo, sendo caracterizada como um componente de um sistema judiciário e passando a ser aceita socialmente, porém não perdeu seu caráter vingativo, sendo esse apenas suavizado, pois não poderia ser aplicado por particulares.

Nesse sentido, assevera Oswaldo Henrique Duek Marques $(2008$, p. 1) que, apesar das atuais teorias sobre a pena e o Direito Penal, baseadas em estudos progressistas, no ponto de vista prático ainda apresenta conotações arcaicas, possuindo forte influência da vingança e do castigo por intermédio de um aspecto mítico cultural. Tais elementos impedem que a pena possa atingir as suas finalidades de prevenção e de socialização.

Mesmo, porém, diante de um sistema judicial que dá destaque ao sistema punitivo retributivo, é inegável o avanço em relação ao sistema penal observado em um passado não muito distante, bem como na própria realidade vivenciada nos dias atuais no Brasil. Mesmo, todavia, não sendo constituído por meios atrozes de punição, ainda há, em nosso sistema penal, resquícios de um passado violento, fato que faz com que a pena seja sempre vista como um castigo. Por esse motivo, dificilmente o sistema conseguirá alcançar seu objetivo, pois nesse processo de punição sempre haverá a presença da violência bem como o caráter de vingança.

Segundo Edgar Hrycylo Bianchini (2012, p. 72), "o Estado tem o poder e o dever de estruturar o sistema judiciário [...] e instituir mecanismos que não atinjam a dignidade de seus cidadãos envolvidos no conflito e que, muito menos, os submetam a um tratamento desumano ou degradante". Ademais, no atual sistema retributivo tanto a vítima quanto o ofensor possuem suas dignidades violadas, mesmo com o sistema penal sendo "calcado nos mesmos princípios basilares que formam o Estado nacional e que têm como principal finalidade e fundamento a dignidade da pessoa humana" (BIANCHINI, 2012, p. 77).

Nesse cenário, o ofensor possui sua dignidade violada ao ser exposto a um sistema prisional degradante, superlotado, sem as mínimas condições da ocorrência de um processo de ressocialização adequado. Já a vítima, por ser vista como um mero objeto necessário para a movimentação do processo penal, é tratada sem o mínimo cuidado psicológico. Sobre essas divergências que ocorrem entre a teoria e a prática, Edgar Hrycylo Bianchini (2012, p. 80) assevera:

Uma sociedade que prima pela dignidade do ser humano e por princípios máximos norteadores do direito não pode mudar seus valores diante da agressão. Não há mutabilidade dos princípios de acordo com o criminoso ou de acordo com a sua moral. Eles subsistem independentemente de quem recebe a luz de sua projeção.

Ainda sobre o tratamento despendido às partes que compõem a lide, Vanessa De Biassio Mazzutti (2012, p. 90) realiza uma análise na qual ressalta o atual papel que a vítima e o ofensor possuem no sistema penal brasileiro. Para a autora, a vítima não possui o status de protagonista na solução do crime, posição essa que é ocupada pelo Estado. Em consequência desse tratamento, há cada vez mais a ocorrência de desamparo às partes, em que tanto vítima quanto ofensor possuem seus direitos fundamentais desrespeitados dentro da relação jurídica. 
A Justiça Restaurativa, ainda, configura-se em uma prática nova no Brasil, possuindo suas origens na Nova Zelândia, onde surgiu como fruto de uma tradição da Tribo Aborígene Maori, a qual tinha, como costume, a reunião da família e da comunidade para a resolução dos conflitos que ocorriam entre eles (LEAL, 2014, p. 54). Nos Estados Unidos e na Europa tal prática foi recriada nas décadas de 70 e 80 do século 20. Com a aplicação da Justiça Restaurativa nesses países, houve a observação de uma notável eficácia na resolução dos conflitos.

A Justiça Restaurativa, contudo, não pode ser vista como uma solução que substituirá o sistema penal existente, pois não é a resposta para todas as situações conflituosas. Nesse sentido, Marcelo Gonçalves Saliba (2009, p. 179) esclarece que a justiça restaurativa não existe para eliminar ou substituir a função do Estado. Ademais, a inafastabilidade da justiça é fundamental no Estado Democrático de Direito.

De acordo com Carlos Eduardo de Vasconcelos (2015, p. 428), a fonte que autoriza a execução dos projetos de Justiça Restaurativa apresentados no Brasil é o Relatório do Instituto Latino Americano das Nações Unidas para a Prevenção do Delito e Tratamento do Delinquente (Ilanud), em que se contempla a definição de Justiça Restaurativa estabelecida pela Organização das Nações Unidas - ONU.

Tal definição é dada pela Resolução no 2002/12 do Conselho Social e Econômico da ONU - o Ecosoc. Conforme os ensinamentos de Leonardo Sica (2009, p. 423), essa Resolução aborda temas como princípios da Justiça Restaurativa, bem como as diversas formas em que ela pode ser aplicada em cada ordenamento jurídico, sendo adaptável e compatível a todos.

No Brasil, em 31 de maio de 2016 o Conselho Nacional de Justiça - CNJ - aprovou a Resolução n. 225, a qual dispõe sobre a Política Nacional de Justiça Restaurativa no âmbito do Poder Judiciário. O principal objetivo é que as práticas restaurativas sejam incentivadas e cada vez mais aplicadas em diversos tipos de conflitos, podendo ser postas em prática conjuntamente com outros tipos de penalizações.

Raquel Tiveron (2014, p. 379), entretanto, aponta o problema da inexistência de legislação específica no Brasil que englobe a temática. Dessa maneira, a aplicação da Justiça Restaurativa fica restrita aos conflitos que podem ser solucionados por meio da justiça consensual. Possui, portanto, possibilidade de aplicação nos Juizados Especiais Criminais, bem como em conflitos que envolvem a prática de atos infracionais.

O encontro é realizado entre vítima, ofensor e outras pessoas relevantes ao caso, no qual todas terão a oportunidade de trocar informações, realizarem questionamentos e reflexões, bem como colocarem-se umas nos lugares das outras e tentar imaginar o que é viver a experiência tanto de praticar o ato violento e viver suas motivações quanto de recebê-lo. Tal encontro será realizado por um mediador, também chamado de facilitador, o qual irá promover o encontro e conduzir as trocas de informações (GIAMBERARDINO; ZILIOTTO, 2015, p. 39).

Quanto à inclusão ou participação, é estabelecida uma condição de paridade entre as partes, na qual vítima, ofensor e comunidade constituem um triângulo, prevalecendo um ambiente de diálogo e respeito para a busca da justiça (LEAL, 2014, p. 55). Dessa forma, é outorgada às partes uma participação ativa e concreta para a resolução do conflito. 


\title{
Democracia
}

É nesse cenário que surge a reflexão: Hoje, a vítima e o ofensor recebem um tratamento compatível com o conceito e o conteúdo mínimo pertinentes ao princípio da dignidade da pessoa humana? Ao analisar a ideologia empregada pelo atual sistema de justiça, observa-se que os sujeitos que compõem o Judiciário não tratam vítima nem ofensor como pessoas que possuem fins em si mesmos, mas, sim, como objetos de um sistema que busca ganhadores e perdedores em detrimento da efetiva busca pela justiça. Tal resultado, contudo, pode ser diferente com a aplicação da Justiça Restaurativa.

\section{A DIGNIDADE DA PESSOA HUMANA COMO PRINCÍPIO DA JUSTIÇA RESTAURATIVA A PARTIR DA VISÃO KANTIANA}

Conforme a visão de Kant, a dignidade da pessoa humana é fundamentada no fato de a pessoa ser considerada um fim em si mesma e não um mero objeto. Nessa seara, observa-se que os indivíduos não estão recebendo esse tipo de tratamento por parte do atual direito penal, o qual trata tanto o ofensor quanto a vítima como meras peças de um processo que possui uma finalidade totalmente estatal.

Nesse sentido, assim observa Oscar Vilhena Vieira (2006, p. 68) sobre a visão kantiana a respeito da violação do princípio da dignidade da pessoa humana:

\begin{abstract}
Se todas as pessoas são um fim em si, todas devem ser respeitadas. E ser "fim em si" significa ser considerado como feixe de razão e sentimentos que não podem ser injustificadamente suprimidos. Essa noção de imparcialidade impõe que as pessoas se tratem com reciprocidade não apenas como uma medida de prudência, mas como um imperativo derivado da assunção de que o outro tem mesmo valor que atribuo a mim mesmo - portanto, é merecedor do mesmo respeito. A reciprocidade derivada do princípio da dignidade humana não pode, assim, ser confundida com a reciprocidade instrumental, que aparece de forma mais clara no contrato hobbesiano, onde eu o respeito apenas porque eu espero que você me respeite, e isso é extremamente conveniente para mim.
\end{abstract}

Ademais, conforme descreve Iran Chaves Garcia Júnior (2017, p. 141), "sob a perspectiva de pensadores como Immanuel Kant, a concepção de dignidade da pessoa humana fundamenta-se de forma sólida e prevalece no pensamento filosófico atual". Considerando tais reflexões, pode-se, então, realizar um paralelo entre o conceito atribuído à dignidade da pessoa humana a partir de Kant - o qual é o mais aceito na contemporaneidade - com os valores atribuídos à uma nova forma de resolução de conflitos: A Justiça Restaurativa.

$\mathrm{Na}$ obra Fundamentação da Metafísica dos Costumes, Immanuel Kant expressa sua preocupação acerca do entendimento sobre a dignidade da pessoa humana, esboçando o que, mais tarde, seria compreendido como um dos conceitos deste elementar princípio:

A vontade é concebida como a faculdade de se determinar a si mesmo a agir em conformidade com a representação de certas leis. E uma tal faculdade só se pode encontrar em seres racionais. Ora aquilo que serve à vontade de princípio objectivo da sua autodeterminação é o fim (Zweck), e este, se é dado pela só razão, tem de ser válido igualmente para todos os seres racionais. O que pelo contrário contém apenas o princípio da possibilidade da acção, cujo efeito é um fim, chama-se meio (2007, p. 67). 
Kant desenvolve, contudo, um conceito de dignidade humana pautado na racionalidade, pela qual percebe que o ser humano deve sempre ser considerado um fim em si mesmo, regido pela autonomia da vontade, tendo em vista não ser utilitário. Nas palavras de Kant (2007, p. 77), "no reino dos fins tudo tem ou um preço ou uma dignidade. Quando uma coisa tem um preço, pode-se pôr em vez dela qualquer outra como equivalente; mas quando uma coisa está acima de todo o preço e, portanto, não permite equivalente, então tem ela dignidade".

Conforme as observações de Michael J. Sandel (2012, p. 155-156), a concepção de dignidade humana abordada por Kant é proposta em decorrência da razão, do respeito à humanidade e da capacidade racional, a qual é inerente ao ser humano. Diferencia, portanto, o respeito das outras formas de relações humanas, como o amor, a empatia e a solidariedade.

Partindo dessas premissas, pode-se observar a intrínseca relação existente entre o Princípio da Dignidade da Pessoa Humana e os valores das práticas restaurativas, acentuando-se as divergências existentes com o sistema penal retributivo. Conforme destaca Howard Zehr (2008, p. 74), "a justiça retributiva define o Estado como vítima, define o comportamento danoso como violação de regras e considera irrelevante o relacionamento entre vítima e ofensor".

No mesmo sentido, ressalta Raffaella Pallamolla (2009, p. 46): “o direito penal esqueceu da vítima ao tratar apenas da 'proteção de bens jurídicos' desde o viés do castigo àquele que cometeu um delito, e negligenciou o dano causado à vítima e a necessidade de reparação".

Já sob o olhar restaurativo, Howard Zehr (2008, p. 74) explica que "a lente restaurativa identifica as pessoas como vítimas e reconhece a centralidade das dimensões interpessoais. As ofensas são definidas como danos pessoais e como relacionamentos interpessoais". Dessa forma, ressalta que o crime é uma violação de pessoas e, também, de sentimentos, portanto as necessidades básicas inerentes à pessoa humana devem ser consideradas nesse processo de responsabilização pelo dano ocasionado.

Dessa forma, observa-se que, para o atual Direito Penal, tanto vítima quanto ofensor são tratados como objetos de uma lide, não havendo a mínima consideração por seus sentimentos e necessidades. Já para a Justiça Restaurativa, pode inclusive ser empregada a máxima já defendida por Kant ao afirmar que "a pessoa não pode ser tratada, nem por outra pessoa nem por si mesma, meramente como meio" (CORDEIRO, 2012, p. 66).

Para que tal objetivo possa ser alcançado, a Justiça Restaurativa pode ser um instrumento para que ocorra a real efetividade do Princípio da Dignidade da Pessoa Humana no Processo Penal, o qual, teoricamente, já existe, mas pode alcançar resultados mais reais e satisfatórios.

Sobre a realidade que o ofensor encontra durante o seu processo de punição imposta pelo Estado, Howard Zehr (2008, p. 37) tece as seguintes considerações:

Todo o entorno carcerário é estruturado com o fim de desumanizar. Os prisioneiros recebem um número, um uniforme, pouco ou nenhum espaço pessoal. São privados de praticamente todas as oportunidades de tomar decisões e exercer poder pessoal. De fato, o foco de todo o ambiente é a obediência e o aprendizado de aceitar ordens. Numa situação assim a pessoa tem poucas escolhas. Ele ou ela talvez aprendam a obedecer, a ser submissos, e essa é a reação que o sistema prisional incentiva. Mas é justamente a reação que menos propiciará uma transição bem sucedida para a liberdade da vida lá fora. 


\section{Humanos e \\ Democracia}

Com os valores restaurativos, tanto vítima quanto ofensor possuem um tratamento enquanto indivíduos que compõe fins em si mesmos e não meros objetos. Possuem suas dignidades preservadas ao serem tratados de maneira pessoal, tendo suas histórias resgatadas, ouvidas e transformadas. A vítima também possui um papel de destaque, não sendo apenas ouvida como mera informante de fatos, mas, sim, tendo seus sentimentos e traumas considerados, tratados, tendo inclusive voz ativa para conversar com o ofensor e tentar compreender a origem do conflito.

Outro aspecto que possui grande relação entre a Justiça Restaurativa e a teoria kantiana acerca da dignidade da pessoa humana é a autonomia da vontade. A Justiça Restaurativa possui vários princípios, os quais podem ser encontrados no artigo 20 da Resolução no 225/2016 do Conselho Nacional de Justiça (2017), sendo eles a corresponsabilidade, a reparação dos danos, o atendimento às necessidades de todos os envolvidos, a informalidade, a voluntariedade, a imparcialidade, a participação, o empoderamento, a consensualidade, a confidencialidade, a celeridade e a urbanidade.

O princípio da voluntariedade é pautado na premissa de que as partes devem demonstrar a vontade própria em participar da prática restaurativa. Além de constituir um dos elementos para a efetividade do círculo restaurativo, pode-se atribuir a esse caráter voluntário o fato de que ainda não existe no ordenamento jurídico brasileiro uma lei que determine, formalmente, o procedimento restaurativo como um devido processo legal (PINTO, 2005, p. 33). A atuação dos envolvidos demanda a inexistência de qualquer forma de coação, devendo ser precedida de esclarecimentos sobre as formas de atuação da Justiça Restaurativa (BIANCHINI, 2012, p. 118).

A partir dessas considerações sobre o Princípio da Voluntariedade aplicado à Justiça Restaurativa, pode-se, então, realizar a comparação à outra formulação do Imperativo Categórico de Immanuel Kant, a qual trata da autonomia da vontade. A partir desse pensamento, Karine da Silva Cordeiro (2012, p. 67) pondera que, para Kant, não existe dignidade sem autonomia, e que somente há autonomia quando o indivíduo se submete à lei da qual ele é o criador. Desta forma, a dignidade do ser racional está na capacidade de criar as leis que regem a sociedade, bem como na possibilidade de obedecer estas leis.

É importante ressaltar, portanto, que, na visão de Kant, a autonomia só existe quando a vontade do sujeito é exercida, o que pode ser observado na participação e na concretização do processo restaurativo, no qual o sujeito possui a autonomia necessária para externar a sua vontade positiva ou negativa em participar de um círculo restaurativo para a composição do conflito.

O último aspecto comparativo a ser observado entre a teoria Kantiana e a Justiça Restaurativa é a dimensão comunitária vislumbrada na filosofia de Kant (CORDEIRO, 2012, p. 67). Destarte, o tripé do diálogo restaurativo é formado pela vítima, pelo ofensor e pela comunidade. Essa última, constitui o terceiro pilar do processo de restauração.

César Barros Leal (2014, p. 229) salienta que o papel da comunidade é decisivo, e reconhece que ao final do conflito a comunidade deverá atuar para que a vítima tenha uma efetiva restauração, bem como operar para a reintegração do ofensor. Isso, porém, não irá significar que a conduta delituosa foi esquecida, mas, sim, que ela foi transformada à luz da Justiça Restaurativa. 
Na construção realizada por Kant acerca do aspecto comunitário da Dignidade da Pessoa Humana, conforme comenta Ingo Wolfgang Sarlet (2006, p. 61), sempre houve a ideia de um sentimento de dever de respeito perante os outros membros que compõem a comunidade; ademais "pelo fato de a dignidade da pessoa encontrar-se ligada à condição humana de cada indivíduo, não há como descartar uma necessária dimensão comunitária (ou social) desta mesma dignidade de cada pessoa e de todas as outras pessoas".

Tal abrangência comunitária da dignidade humana pode também ser vista como um elemento de restrição ou de heteronomia representando a sociedade, tendo em vista que as relações estabelecidas entre os indivíduos constituem os contornos da dignidade humana (BARROSO, 2014, p. 87).

Diante das considerações expostas, tem-se, portanto, a correlação entre a faceta comunitária da dignidade humana e um dos elementos da Justiça Restaurativa. A comunidade, como tripé do processo restaurativo, possui fundamental importância no processo de reintegração social do ofensor, bem como possui papel essencial para a constatação das motivações das práticas delituosas, podendo, assim, exercer um papel preventivo, objetivando a não realização de atos infracionais e crimes, bem como a não reincidência.

\section{CONCLUSÃO}

Ao final do presente artigo foi possível concluir que o conceito de Dignidade da Pessoa Humana passou por grandes transformações e evoluções ao longo da história da humanidade e, contemporaneamente, possui sua essência pautada na concepção de Immanuel Kant, o qual propôs que nenhuma pessoa pode ser considerada como um objeto. Ademais, para tal filósofo, para que uma pessoa tenha dignidade faz-se necessário que ela seja considerada como um fim em si mesma.

Com isso, objetiva-se a análise no que se refere à efetivação do Princípio da Dignidade da Pessoa Humana na aplicação de penas e na condução do processo penal no atual sistema jurídico criminal brasileiro. Conclui-se, contudo, que, com a atual abordagem realizada pela justiça comum, os sujeitos do processo não possuem suas dignidades respeitadas, sendo tratados como meros objetos, os quais são utilizados para que uma resposta seja oferecida à sociedade e não para eles mesmos, os quais são os mais interessados e afetados pelo conflito.

Destarte, o renascer de um antigo método de resoluções de conflitos pode auxiliar na busca pela efetivação da dignidade humana na justiça comum. A Justiça Restaurativa trata os sujeitos do processo como pessoas, preocupando-se com suas necessidades pessoais, emoções e sentimentos. Mediante a fomentação do diálogo e da responsabilização, as práticas restaurativas buscam respostas que vítimas nunca tiveram; já para os ofensores, proporcionam espaços de reflexão e conscientização jamais proporcionados pela justiça comum.

A Justiça Restaurativa não irá substituir a justiça tradicional, porém poderá ser aplicada de forma complementar. Para que isso ocorra, em primeiro lugar, é necessário que haja o envolvimento de todos os sujeitos do processo, bem como de todos os envolvidos na execução dos projetos piloto de Justiça Restaurativa. 


\section{Humanos e \\ Democracia}

Assim, percebe-se que a resolução dos conflitos por meio da aplicação complementar da Justiça Restaurativa irá proporcionar maior humanização do processo, buscando a efetivação do Princípio da Dignidade da Pessoa Humana. Entende-se, dessa forma, que a resposta dada à situação-problema deste artigo é capaz de oferecer a solução ao questionamento realizado. Desse modo, conforme a concepção kantiana de Dignidade da Pessoa Humana, a Justiça Restaurativa poderia ser utilizada como um método alternativo ou complementar de resoluções de conflitos para que tal dignidade possa ser alcançada.

\section{REFERÊNCIAS}

BARROSO, Luís Roberto. A dignidade da pessoa humana no Direito Constitucional Contemporâneo: a construção de um conceito jurídico à luz da jurisprudência mundial. Tradução Humberto Laport de Mello. Belo Horizonte: Fórum, 2014.

BIANCHINI, Edgar Hrycylo. Justiça restaurativa: um desafio à práxis jurídica. Campinas, SP: Servanda Editora, 2012.

BRASIL. Constituição (1988). Constituição da República Federativa do Brasil de 1988. Disponível em: http://www. planalto.gov.br/ccivil_03/constituicao/constituicao.htm. Acesso em: 30 jul. 2017.

CONSELHO NACIONAL DE JUSTIÇA. Resolução no 225 de 31 de maio de 2016. Dispõe sobre a Política Nacional de Justiça Restaurativa no âmbito do Poder Judiciário e dá outras providências. Disponível em: http://www.cnj.jus. br///images/atos_normativos/resolucao/resolucao_225_31052016_02062016161414.pdf. Acesso em: 1o ago. 2017.

CORDEIRO, Karine da Silva. Direitos fundamentais sociais: dignidade da pessoa humana e mínimo existencial. Porto Alegre: Livraria do Advogado, 2012.

DIMOULIS, Dimitri; MARTINS, Leonardo. Teoria Geral dos Direitos Fundamentais. 5. ed. rev. atual. ampl. São Paulo: Atlas, 2014.

GARCIA JÚNIOR, Iran Chaves. A justiça restaurativa como instrumento para garantir a dignidade da pessoa humana. Revista Justiça do Direito, Passo Fundo, v. 31, n. 1, jan./abr. 2017.

GIAMBERARDINO, Pedro Ribeiro; ZILIOTTO, Flávia Palmieri de Oliveira. Justiça restaurativa e a socioeducação. Paraná: Cadernos de Socioeducação; Secretaria da Justiça, Cidadania e Direitos Humanos, 2015.

KANT, Immanuel. Fundamentação da metafísica dos costumes. Tradução Paulo Quintela. Lisboa, Portugal: Edições 70, 2007.

LARENZ, Karl. Metodologia da Ciência do Direito. Trad. José Lamego. 6. ed. Lisboa: Fundação Calouste Gulbenkian, 1997.

LEAL, César Barros. Justiça restaurativa amanhecer de uma era: aplicação em prisões e centros de internação de adolescentes infratores. Curitiba: Juruá, 2014.

MARQUES, Oswaldo Henrique Duek. Fundamentos da pena. 2. ed. São Paulo: WMF Martins Fontes, 2008.

MAZZUTTI, Vanessa De Biassio. Vitimologia e direitos humanos: o processo penal sob a perspectiva da vítima. Curitiba: Juruá, 2012.

PALLAMOLLA, Raffaella da Porciuncula. Justiça restaurativa: da teoria à prática. 1. ed. São Paulo: Ibccrim, 2009. PINTO, Renato Sócrates Gomes Pinto. Justiça restaurativa é possível no Brasil? In: SLAKMON, Catherine; VITTO, Renato Campos Pinto de; PINTO, Renato Sócrates Gomes. Justiça restaurativa. Brasília, DF: MJ; PNUD, 2005.

SALIBA, Marcelo Gonçalves. Justiça restaurativa e paradigma punitivo. Curitiba: Juruá, 2009.

SANDEL, Michael J. Justiça - o que é fazer a coisa certa. Tradução Heloísa Matias e Maria Alice Máximo. 5. ed. Rio de Janeiro: Civilização Brasileira, 2012.

SARLET, Indo Wolfgang. As dimensões da dignidade da pessoa humana. Revista Brasileira de Direito Constitucional-RBDC, n. 9, Jan./jun. 2007.

SARLET, Indo Wolfgang. Dignidade da pessoa humana e direitos fundamentais na Constituição Federal de 1988. 4. ed. rev. atual. Porto Alegre: Livraria do Advogado, 2006.

SICA, Leonardo. Bases para o modelo brasileiro de justiça restaurativa. De Jure: Revista Jurídica do Ministério Público do Estado de Minas Gerais, Belo Horizonte, n. 12, p. 411-447, jan./jun. 2009. Disponível em: https://bdjur. stj.jus.br/jspui/bitstream/2011/28064/bases_para_modelo_brasileiro.pdf. Acesso em: 16 jul. 2017.

TIVERON, Raquel. Justiça restaurativa: a construção de um novo paradigma de justiça criminal. Brasília, DF: Thesaurus, 2014. 
VASCONCELOS, Carlos Eduardo de. Mediação de conflitos e práticas restaurativas. 4. ed. rev., atual. e ampl. Rio de Janeiro: Forense; São Paulo: Método, 2015.

VIEIRA, Oscar Vilhena. Direitos fundamentais: uma leitura da jurisprudência do STF. São Paulo: Malheiros, 2006. ZEHR, Howard. Trocando as lentes: um novo foco sobre o crime e a justiça. Tradução Tônia Van Acker. São Paulo: Palas Athena, 2008. 